\title{
MATERNAL TRANSMISSION EFFICIENCY OF WOLBACHIA SUPERINFECTIONS IN AEDES ALBOPICTUS POPULATIONS IN THAILAND
}

\author{
PATTAMAPORN KITTAYAPONG, KATHY J. BAISLEY, ROSIE G. SHARPE, VISUT BAIMAI, AND SCOTT L. O’NEILL \\ Department of Biology, Faculty of Science, Mahidol University, Bangkok, Thailand; Section of Vector Biology, \\ Department of Epidemiology and Public Health, Yale University School of Medicine, New Haven, Connecticut
}

\begin{abstract}
We examined the transmission efficiency of 2 strains of Wolbachia bacteria that cause cytoplasmic incompatibility in field populations of Aedes albopictus by polymerase chain reaction assay. We found mainland and island populations throughout Thailand to be superinfected with group A and B bacteria. Of 320 Wolbachia-positive adult mosquitoes, $97.5 \%$ were infected with both groups. Single infected individuals of each Wolbachia group were encountered in nearly equal numbers. We screened 550 offspring from 80 field-collected mothers and found the transmission efficiency of group A Wolbachia to be $96.7 \%$ and that of group B Wolbachia to be $99.6 \%$. Mothers that did not transmit both Wolbachia infections to all of their offspring were significantly larger in size than those with perfect transmission fidelity. We discuss our findings in relation to the prospects of the use of Wolbachia as a gene-driving mechanism.
\end{abstract}

\section{INTRODUCTION}

Cytoplasmic incompatibility is a common phenomenon in insects, caused by maternally inherited bacteria of the genus Wolbachia. ${ }^{1}$ When a Wolbachia-infected male mates with an uninfected female, the eggs or embryos most commonly die. The net effect is a decrease in the fitness of uninfected females, which over time results in the spread of Wolbachia infection through the population. Individuals may possess more than one strain of Wolbachia, ${ }^{2,3}$ in which case cytoplasmic incompatibility occurs between superinfected individuals if the female is infected with fewer Wolbachia strains than the male with which she mates. The net effect is a decrease in the fitness of such females, and thus the higher-level superinfection spreads., ${ }^{4,5}$ Phylogenetic analyses of $16 \mathrm{~S}$ ribosomal RNA and fts $Z$ gene sequences have established that Wolbachia associated with host reproductive alterations form a monophyletic clade in the $\alpha$-proteobacteria. ${ }^{3,6-8}$ Within this clade, the 2 major groups of Wolbachia, designated $\mathrm{A}$ and $\mathrm{B}$, are estimated to have diverged 58-67 million years ago. ${ }^{3}$

It has been suggested that the capacity of Wolbachia for population invasion may be harnessed to push desirable genes, such as those that block parasite transmission, into natural populations of arthropod disease vectors. ${ }^{9-11}$ These bacteria have a number of properties that make them particularly attractive for this goal, including a wide host range, ${ }^{12}$ wide tissue distribution, ${ }^{13}$ and an ability to sweep into insect populations repeatedly. Such repeated invasions are made possible by the independent cytoplasmic incompatibility properties of each Wolbachia strain, as demonstrated by the dynamics of superinfections in several insect hosts.,5,14

The success of Wolbachia as a gene-driving mechanism is critically dependent on the efficiency of its maternal transmission under field conditions. ${ }^{11}$ This parameter has only been measured in Drosophila, where it averages $96.4 \%$ in field-collected Drosophila melanogaster ${ }^{15}$ and $95-97 \%$ in field-collected Drosophila simulans, with transmission efficiency of individual females varying 60-100\%. ${ }^{16,17}$ In contrast, perfect maternal transmission has been recorded in several hundred lines of laboratory-bred Drosophila simulans. ${ }^{18}$ Although good data exist for transmission efficiencies of Wolbachia in Drosophila populations, almost no data are available for other species. ${ }^{11}$ In addition, no data have been gathered on the transmission efficiencies of Wolbachia superinfections under field conditions. Laboratory studies suggest that they may be lower than single infections. ${ }^{4}$ We have measured the vertical transmission efficiency of Wolbachia superinfection in field populations of the Asian tiger mosquito Aedes albopictus (Skuse), a vector of dengue fever. ${ }^{19}$

\section{MATERIALS AND METHODS}

Mosquito specimens. Adult mosquitoes were collected from 21 provinces in mainland Thailand and 7 islands located 20-70 km offshore between August 1995 and December 1997 (Figure 1). Collections were made with Centers for Disease Control and Prevention light traps (BioQuip, Gardena, CA) and mosquito landing catches by standard techniques. ${ }^{20}$ Individuals were identified to species level with the morphological keys of Buei ${ }^{21}$ and of Rattanarithikul and Panthusiri. ${ }^{22}$ Specimens that could not be processed immediately were stored at $-70^{\circ} \mathrm{C}$ for later use.

Polymerase chain reaction (PCR) amplification. Mosquitoes were screened for the presence of Wolbachia by PCR with general $f t s Z$ bacterial cell cycle gene primers. ${ }^{4,23}$ Individual mosquitoes were dissected and the ovaries or testes removed in distilled water by use of sterile dissecting equipment. Crude DNA extractions were performed by homogenizing gonadal tissue in $100 \mu \mathrm{l}$ of STE buffer $(100 \mathrm{mM}$ $\mathrm{NaCl}, 10 \mathrm{mM}$ Tris-HCl, $1 \mathrm{mM}$ EDTA, $\mathrm{pH} 8.0$ ), by use of the methods of O'Neill and others. ${ }^{6}$ One microliter of supernatant was used as the DNA template in the PCR reaction. Specimens yielding a product of the expected size (730 base pairs [bp]) were scored as positive for Wolbachia. Wolbachia-infected D. simulans or Ae. albopictus were used as a positive control. Negative controls were randomly included to check for contamination.

The PCR amplifications were carried out on a Hybaid Omnigene thermal cycler (Hybaid Limited, Middlesex, United Kingdom) with $20 \mu \mathrm{L}$ reaction volumes: $2 \mu \mathrm{L} 10 \times$ buffer (Promega, Madison, WI), $2 \mu \mathrm{L} 25 \mathrm{mM} \mathrm{MgCl}_{2}, 0.5 \mu \mathrm{L}$ dNTPs (10 mM each), $0.5 \mu \mathrm{L} 20 \mu \mathrm{M}$ forward and reverse primers, and $1 \mathrm{U}$ of DNA polymerase (Promega). The following temperature profiles were used: an initial denaturation at $95^{\circ} \mathrm{C}$ for $3 \mathrm{~min}$, then $95^{\circ} \mathrm{C}$ for $1 \mathrm{~min}, 50^{\circ} \mathrm{C}$ for 1 


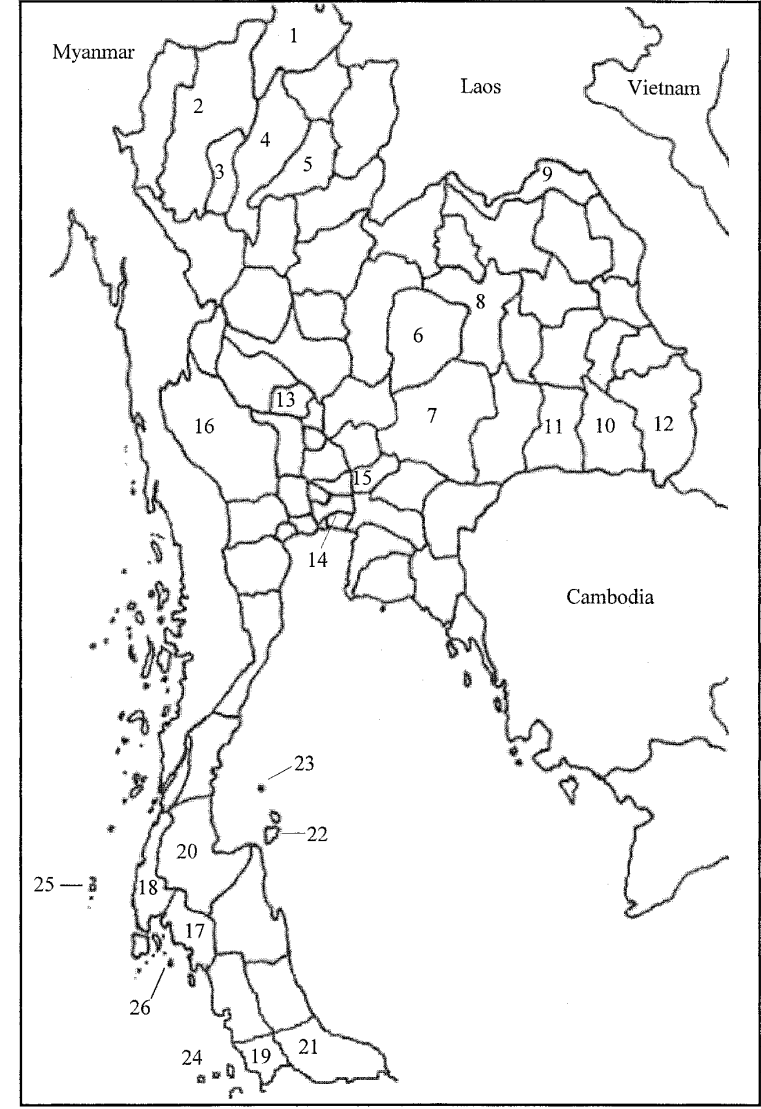

FIGURE 1. Map of Thailand showing the locations of provinces and islands where field collections were made. $1=$ Chiangrai; $2=$ Chiangmai; 3 = Lamphun; 4 = Lampang; 5 = Phrae; 6 = Chaiyaphum; $7=$ Nakornratchasima; $8=$ Khonkaen; $9=$ Nongkai; 10 = Sisaket;11 = Surin; $12=$ Ubonratchathani; $13=$ Chainat; $14=$ Chachoengsao; $15=$ Nakornnayok; $16=$ Kanchanaburi; $17=$ Krabi $18=$ Phang Nga; $19=$ Satul; $20=$ Suratthani; $21=$ Songkhla; 22 $=$ Samui Island; $23=$ Tao Island; $24=$ Adang, Lipe, and Tarutao Islands; $25=$ Miang Island; $26=$ Phi-phi Island.

min, and $72^{\circ} \mathrm{C}$ for 1 min per cycle for 30 cycles. The PCR products were run on a $1 \%$ agarose gel with a $1-\mathrm{kb}$ ladder (Gibco BRL, Gaithersburg, MD) to determine the presence and size of amplified DNA.

We did not attempt to measure the number of uninfected individuals because the assay we used is susceptible to falsenegative findings in this mosquito species, presumably due to PCR inhibitory compounds present in some DNA extractions. Because we could not confirm the infection status of uninfected individuals, this study is restricted to an analysis of the production of single infected offspring from superinfected mothers and an estimate of the frequency of single infection in the field. Among field-caught females, we were able to confirm the infection status of all single infected individuals by typing 2 of their offspring.

Infections were typed into Wolbachia groups A and B with 1 of 2 methods: 1) restriction fragment length polymorphism (RFLP) analysis with EcoRV (Promega) to digest the $f t s Z$-amplified product, ${ }^{4}$ or 2 ) PCR screening with groupspecific primers designed from the bacterial outer surface protein gene $w s p .{ }^{24}$ For the RFLP analysis, specimens without a restriction site were classified as group A bacteria; those with a single EcoRV restriction site were classified as group B. Group A and B wsp primers yield fragments of $556 \mathrm{bp}$ and $442 \mathrm{bp}$, respectively.

Group A and B wsp PCR products were sequenced to confirm the correct amplification and to identify the specific strain of Wolbachia infection in wild-caught Ae. albopictus. Products were cleaned by means of spin columns (Wizard PCR Preps, Promega) and cloned into a pGEM-T vector (Promega). Plasmids were extracted (Wizard Minipreps, Promega) and sequenced in both directions with primers $\mathrm{T} 7$ and SP6 (AmpliTaq DNA polymerase, FS, Applied Biosystems on an automated sequencer, ABI 377, Perkin-Elmer, Norwalk, CT).

Measure of maternal-transmission efficiency. Field-collected adult female mosquitoes from every region of Thailand were selected at random, fed blood, then transferred to an individual vial to lay eggs. After oviposition, parent females were PCR tested to confirm their Wolbachia infection status. Random samples of adult F1 offspring from each female were also PCR screened. In addition, for the Samui Island population, wing-length measurements were obtained for all parent females. F1 larvae from each female were reared under insectary conditions in $1 \mathrm{~L}$ of distilled water in separate autoclaved trays. Larvae were fed daily on autoclaved fish-food pellets until pupation.

Statistical analysis. The significance of differences in Wolbachia infection and transmission frequency between mosquito groups was evaluated with the chi-square test by Statistix version 4.1 (Analytical Software, Tallahassee, FL). Mean wing lengths between groups were compared with Student's $t$-test. $P<0.05$ was considered significant.

\section{RESULTS}

Field single and double infection frequencies. Amplified PCR products were confirmed as belonging to either group A or B Wolbachia clades by sequencing. The group A infection was from the AlbA subgroup and the group B infection was from the Pip subgroup, as described by Zhou and others. ${ }^{24}$

A total of 320 individuals tested positive for Wolbachia by PCR screening (Table 1). Of these, 312 (97.5\%) were double-infected with Wolbachia groups A and B bacteria. Only 8 single-infected individuals were detected, 6 from central Thailand and 2 from southern Thailand. Single infections of both Wolbachia groups were encountered, with 5 individuals positive for group B bacteria only and 3 positive for group A only. The frequency of single infections did not differ significantly between geographical regions (chi-square $=4.26$, degrees of freedom $[\mathrm{df}]=2, P=0.13$ ).

Of the 320 Wolbachia-positive individuals, 110 were collected from island populations off the east and west coasts of southern Thailand (Table 1). A total of 108 were superinfected with group A and B Wolbachia (98.2\%). In addition, all individuals tested from the 3 islands located furthest from the mainland, Miang, Lipe, and Adang, were found to be double infected. Miang is located $>60 \mathrm{~km}$ off the Thai mainland, whereas Lipe and Adang are $\sim 70 \mathrm{~km}$ offshore. Only 2 single-infected individuals were detected in collections made from island populations; one from Samui Island was positive for group B Wolbachia only, and one from Tao 
TABLE 1

Frequency of Wolbachia superinfection in field-collected Aedes albopictus from Thailand (includes mainland and island populations)*

\begin{tabular}{|c|c|c|c|c|c|}
\hline $\begin{array}{l}\text { Region and total } \\
\text { infected }(\% \mathrm{AB})\end{array}$ & Province or island & $\mathrm{AB}$ & A only & B only & Total $(\% \mathrm{AB})$ \\
\hline North & Chiangrai & 9 & 0 & 0 & $9(100.0)$ \\
\hline \multirow[t]{4}{*}{$30(100.0)$} & Chiangmai & 17 & 0 & 0 & $17(100.0)$ \\
\hline & Lamphun & 2 & 0 & 0 & $2(100.0)$ \\
\hline & Lampang & 1 & 0 & 0 & $1(100.0)$ \\
\hline & Phrae & 1 & 0 & 0 & $1(100.0)$ \\
\hline Central & Chaiyaphum & 5 & 0 & 0 & $5(100.0)$ \\
\hline \multirow{10}{*}{$128(95.3)$} & Nakornratchasima & 3 & 0 & 0 & $3(100.0)$ \\
\hline & Khonkaen & 17 & 0 & 0 & $17(100.0)$ \\
\hline & Nongkai & 1 & 0 & 0 & $1(100.0)$ \\
\hline & Sisaket & 3 & 0 & 0 & $3(100.0)$ \\
\hline & Surin & 3 & 0 & 0 & $3(100.0)$ \\
\hline & Ubonratchathani & 18 & 0 & 0 & $18(100.0)$ \\
\hline & Chainat & 38 & 0 & 2 & $40(95.0)$ \\
\hline & Chachoengsao & 11 & 0 & 2 & $13(84.6)$ \\
\hline & Nakornnayok & 3 & 0 & 0 & $3(100.0)$ \\
\hline & Kanchanaburi & 20 & 2 & 0 & $22(90.9)$ \\
\hline South & Krabi & 10 & 0 & 0 & $10(100.0)$ \\
\hline \multirow[t]{11}{*}{$162(99.4)$} & Phang Nga & 12 & 0 & 0 & $12(100.0)$ \\
\hline & Satul & 5 & 0 & 0 & $5(100.0)$ \\
\hline & Suratthani & 3 & 0 & 0 & $3(100.0)$ \\
\hline & Songkhla & 17 & 0 & 0 & $17(100.0)$ \\
\hline & Samui Island $\dagger$ & 57 & 0 & 1 & $58(98.3)$ \\
\hline & Tao Island $\ddagger$ & 19 & 1 & 0 & $20(95.0)$ \\
\hline & Lipe Island $\ddagger$ & 5 & 0 & 0 & $5(100.0)$ \\
\hline & Adang Island $\ddagger$ & 5 & 0 & 0 & $5(100.0)$ \\
\hline & Tarutao Island $\ddagger$ & 20 & 0 & 0 & $20(100.0)$ \\
\hline & Miang Island $\ddagger$ & 2 & 0 & 0 & $2(100.0)$ \\
\hline & Phi-phi Island $\ddagger$ & 5 & 0 & 0 & $5(100.0)$ \\
\hline Total & & 312 & 3 & 5 & $320(97.5)$ \\
\hline
\end{tabular}

* Infections were typed into Wolbachia groups A and B by restriction fragment length polymorphism analysis of ftsZ-amplified products, except as indicated.

$\dagger$ Some individuals were typed with group-specific wsp primers.

$\ddagger$ All individuals were typed with group-specific wsp primers.

Island was positive for group A Wolbachia only. The frequency of single infections did not differ significantly between the island and mainland populations (chi-square = 0.36 , df $=1, P=0.55$ ).

Transmission efficiencies. The F1 offspring were obtained from 80 field-collected adult females from 12 provinces throughout Thailand, representing 1 island and 11 mainland locations (Table 2). All parent females were pos-
TABLE 3

Infection status of $\mathrm{F} 1$ offspring from females with imperfect transmission of Wolbachia

\begin{tabular}{llrrrrr}
\hline & & $\begin{array}{c}\text { No. off- } \\
\text { spring } \\
\text { tested }\end{array}$ & & & & \\
Female. offspring of each infection status
\end{tabular}

itive for both A and B group Wolbachia by PCR assay. A total of 550 offspring were PCR screened for Wolbachia, of which 530 (96.4\%) were superinfected with both Wolbachia groups. Transmission efficiency (the fraction of infected offspring produced by infected females) was 96.7\% (532 of 550) for group A bacteria and $99.6 \%$ (548 of 550) for group B bacteria.

The 20 single-infected offspring were produced by 10 mothers, or $12.5 \%$ of all mothers sampled. Eight mothers produced offspring that were single-infected with group B bacteria, one mother produced offspring that were singleinfected with group A bacteria, and one mother produced single-infected offspring of each Wolbachia group (Table 3). The number of mothers producing offspring that were single-infected with group A bacteria was not significantly different from those producing offspring that were single-infected with group B bacteria (chi-square $=3.08, \mathrm{df}=1, P$ $=0.08$ ). Among those females that did not transmit both Wolbachia infections to all their offspring, the proportion of single-infected progeny ranged from $5.6 \%$ (1 of 18 ) to $50 \%$ ( 2 of 4 ), with an overall mean of $17.5 \%$. The number of females producing at least one single-infected offspring did not differ significantly between regions (chi-square $=1.17$, df $=2, P=0.56$ ).

Wing-length measurements were obtained for 41 super-

TABLE 2

Segregation of double Wolbachia infections in F1 progeny of field-collected Aedes albopictus from mainland and island locations*

\begin{tabular}{|c|c|c|c|c|c|c|c|}
\hline \multirow[b]{2}{*}{ Region } & \multirow[b]{2}{*}{ Province or island } & \multirow[b]{2}{*}{ Total no. females } & \multirow{2}{*}{$\begin{array}{l}\text { No. females with imper- } \\
\text { fect transmission }\end{array}$} & \multicolumn{4}{|c|}{ No. F1 progeny of each infection status } \\
\hline & & & & $\mathrm{AB}$ & A & B & Total (\% AB) \\
\hline \multirow[t]{2}{*}{ North } & Chiangrai & 3 & 0 & 21 & 0 & 0 & $21(100.0)$ \\
\hline & Chiangmai & 2 & 0 & 3 & 0 & 0 & $3(100.0)$ \\
\hline \multirow[t]{5}{*}{ Central } & Ubonratchathani & 2 & 0 & 21 & 0 & 0 & $21(100.0)$ \\
\hline & Khonkaen & 5 & 0 & 36 & 0 & 0 & $36(100.0)$ \\
\hline & Chainat & 5 & 0 & 29 & 0 & 0 & $29(100.0)$ \\
\hline & Nakornnayok & 2 & 0 & 12 & 0 & 0 & $12(100.0)$ \\
\hline & Kanchanaburi & 6 & 2 & 48 & 1 & 6 & $55(87.3)$ \\
\hline \multirow[t]{5}{*}{ South } & Satul & 2 & 1 & 17 & 0 & 3 & $20(85.0)$ \\
\hline & Krabi & 3 & 0 & 16 & 0 & 0 & $16(100.0)$ \\
\hline & Songkhla & 3 & 0 & 10 & 0 & 0 & $10(100.0)$ \\
\hline & Phang Nga & 4 & 0 & 33 & 0 & 0 & $33(100.0)$ \\
\hline & Samui Island $\dagger$ & 43 & 7 & 284 & 1 & 9 & 294 (96.6) \\
\hline Total & & 80 & 10 & 530 & 2 & 18 & $550(96.4)$ \\
\hline
\end{tabular}

* Infections were typed into Wolbachia groups A and B by restriction fragment length polymorphism analysis of ftsZ-amplified products, except as indicated.

$\dagger$ Infection status of F1 from some females typed with group-specific wsp primers. 
infected parent females collected from Samui Island, 7 of which did not transmit both Wolbachia infections to all their F1 offspring. Mean wing length was significantly greater in those females that had produced at least one single-infected offspring (2.53 $\mathrm{mm}$ versus $2.37 \mathrm{~mm} ; P=0.04)$.

\section{DISCUSSION}

Our data show that Wolbachia-infected Ae. albopictus field populations in Thailand are predominantly superinfected with 2 different Wolbachia strains (Table 1). The frequency of superinfection in field-collected populations was not significantly different between regions of the country. Among those single-infected individuals sampled, group A and B Wolbachia were encountered in nearly equal numbers ( $n=3$ and 5 , respectively).

The high frequency of superinfections observed in all regions of the country, including remote islands, suggests that both group A and B Wolbachia infections have been present in Ae. albopictus populations in Thailand for a considerable length of time and that both infections are near fixation. Sinkins and others, ${ }^{4}$ in their work with Ae. albopictus, reported a single-strain Wolbachia infection in a colony that originated from Samui Island. In contrast, their colony, founded from females collected on mainland Thailand, was noted to be superinfected. The infection in the Samui colony has since been typed as group A Wolbachia and those in the mainland colony as groups A and B (O'Neill SL, unpublished data). The authors hypothesized that the group A infection might be more ancient and that the group B infection had subsequently swept through Ae. albopictus populations on the Thai mainland but had not yet reached isolated oceanic islands.

However, our data do not support this hypothesis. We sampled remote islands on both coasts of Thailand, including those that were located furthest from the mainland; superinfection was present in all Ae. albopictus populations that we tested. The Samui colony that Sinkins and others ${ }^{4}$ used in their work was founded before 1970; their colony from the mainland was founded in 1992. It is possible that the group B infection spread to Samui, and to other remote islands, in the last 20-30 years. However, given the prevalence of superinfection on remote islands, a more likely explanation is that both infections have been near fixation for much longer, and that the Samui colony material lost the B group infection while in the laboratory.

Our data from field-collected mothers show a high rate of maternal transmission of the Wolbachia superinfection with, on average, $96 \%$ of $\mathrm{F} 1$ offspring from superinfected females receiving both infections (Table 2). Most females passed both infections to all their offspring, with only $12.5 \%$ (10 of 80) of females producing some single-infected progeny. Although not significantly different, more females produced single B infections ( 9 of 80 ) than single A infections ( 2 of 80), suggesting that group A infections may be lost more frequently than group B. This is consistent with earlier studies that suggest that group A Wolbachia are at lower densities than group B Wolbachia in Ae. albopictus and thus would be expected to be transmitted less efficiently. ${ }^{25}$

Of those females with imperfect transmission, 6 produced more than one single-infected offspring. Similar variation in the rates at which females transmit Wolbachia infection has been reported in D. simulans. Turelli and Hoffmann, ${ }^{17}$ in their work with single-infected $D$. simulans, noted that although some females failed to show any segregation in their progeny, others produced nearly 50\% uninfected offspring. Our study did not attempt to measure the proportion of uninfected individuals produced by superinfected mothers. This was due to limitations in the assay that produced a proportion of false-negative results. As a result, our results on transmission efficiency are likely to be an overestimate because it would be expected that superinfected mothers would produce some uninfected offspring, as well as single infected offspring. However, it is reasonable to suppose that the proportion of uninfected offspring would be less than that of single infected offspring from superinfected mothers. ${ }^{4}$

Studies of D. simulans have shown that maternal transmission rates of Wolbachia may vary in response to environmental conditions that affect larval development. ${ }^{1}$ When reared under crowded conditions, $21 \%$ of offspring from superinfected $D$. simulans females were found to be single infected. ${ }^{4}$ Merçot and Poinsot ${ }^{26}$ demonstrated the effect of crowding on wNo strain Wolbachia infection in D. simulans; after 10 generations, $67 \%$ of $w N o$ lines lost their infection. Recent phylogenetic analysis has demonstrated the $w N o$ infection to be the same Wolbachia subgroup as the group B infection in Ae. albopictus. ${ }^{24}$ Clancy and Hoffmann ${ }^{27}$ showed that female $D$. simulans exposed to low doses of tetracycline produced 10-60\% uninfected eggs; the authors suggested that partial curing due to naturally occurring antibiotics may contribute to imperfect maternal transmission in the field. Our data for the Samui Island population showed that fieldcollected females producing at least one single-infected offspring had significantly greater wing lengths than females that transmitted both infections to all offspring. This observation is not consistent with findings in D. simulans, ${ }^{4}$ in which larval stressing resulted in smaller adults and lower Wolbachia transmission rates.

Two explanations may account for our findings in Ae. albopictus. Larger females may have proportionately lower bacterial densities, and therefore they may transmit their infections with lower fidelity. Indeed, infected hosts have been shown to vary in their levels of Wolbachia density. ${ }^{16,25,28,29}$ Alternatively, the larger females may represent a cohort that experienced conditions during larval development that were less favorable for Wolbachia transmission, such as high temperatures or environmental antibiotics.

Because of their capacity for population invasion and cytoplasmic replacement, Wolbachia have been suggested as a driving mechanism for spreading useful genes, such as those that may confer resistance to disease transmission. One essential property of any gene-driving system is that it can be used to achieve repeated population replacements. The high fidelity with which the Ae. albopictus superinfection is passed to offspring in the field further supports the possible use of Wolbachia superinfections for this purpose.

Acknowledgments: We thank Rampa Rattanarithikul and Pitti Mongkalangoon for their help with parts of mosquito collections and morphological identifications, and Kitti Theinthong and Samniang Theinthong for insectary and laboratory assistance. We thank Nina Wedell and Roger Butlin for critically reading the article in manuscript and their helpful suggestions. 
Financial support: This work was supported by the TRF/BIOTEC Special Program for Biodiversity Research and Training (BRT 139026) and the Thailand Research Fund (RTA/38/80008).

Authors' addresses: Pattamaporn Kittayapong and Visut Baimai, Department of Biology, Faculty of Science, Mahidol University, Rama 6 Road, Bangkok 10400, Thailand. Kathy J. Baisley, Hammersmith Medicines Research, Central Middlesex Hospital, Acton Lane, London, NW10 7NS, United Kingdom. Rosie G. Sharpe, School of Biology, University of Leeds, Leeds, LS2 9JT, United Kingdom. Scott L. O'Neill, Section of Vector Biology, Department of Epidemiology and Public Health, Yale University School of Medicine, 60 College Street, New Haven, CT 06520.

Reprint requests: Pattamaporn Kittayapong, Department of Biology, Faculty of Science, Mahidol University, Rama 6 Road, Bangkok 10400, Thailand, Telephone: 66-2-201-5254, Fax: 66-2-247-0079, E-mail: grpkt@mahidol.ac.th.

\section{REFERENCES}

1. Hoffmann AA, Turelli M, 1997. Cytoplasmic incompatibility in insects. O'Neill SL, Hoffmann AA, Werren JH, eds. Influential Passengers. New York: Oxford University Press, 42-80.

2. Werren JH, Windsor D, Guo LR, 1995. Distribution of Wolbachia among neotropical arthropods. Proc R Soc Lond B 262 . 197-204.

3. Werren JH, Zhang W, Guo LR, 1995. Evolution and phylogeny of Wolbachia-reproductive parasites of arthropods. Proc $R$ Soc Lond B 261: 55-63.

4. Sinkins SP, Braig HR, O’Neill SL, 1995. Wolbachia superinfection and the expression of cytoplasmic incompatibility. Proc $R$ Soc Lond B 261: 325-330.

5. Rousset F, Braig HR, O'Neill SL, 1999. A stable triple Wolbachia infection in Drosophila with nearly additive incompatibility effects. Heredity 82: 620-627.

6. O’Neill SL, Giordano R, Colbert AME, Karr TL, Robertson HM, 1992. 16S ribosomal RNA phylogenetic analysis of the bacterial endosymbionts associated with cytoplasmic incompatibility in insects. Proc Natl Acad Sci U S A 89: 26992702.

7. Rousset F, Bouchon D, Pintureau B, Juchault P, Solignac M, 1992. Wolbachia endosymbionts responsible for various alterations of sexuality in arthropods. Proc R Soc Lond B 250: 91-98.

8. Stouthamer R, Breeuwer JAJ, Luck RF, Werren JH, 1993. Molecular identification of the microorganisms associated with parthenogenesis. Nature 361: 66-68.

9. Beard CB, O'Neill SL, Tesh RB, Richards FF, Aksoy S, 1993. Modification of arthropod vector competence via symbiotic bacteria. Parasitol Today 9: 179-183.

10. Sinkins SP, Curtis CF, O’Neill SL, 1997. The potential application of inherited symbiont systems to pest control. O'Neill SL, Hoffmann AA, Werren JH, eds. Influential Passengers. New York: Oxford University Press, 155-175.

11. Turelli M, Hoffmann AA, 1999. Microbe-induced cytoplasmic incompatibility as a mechanism for introducing transgenes into arthropod populations. Insect Mol Biol 8: 243-255.

12. Werren JH, O'Neill SL, 1997. The evolution of heritable symbionts. O'Neill SL, Hoffmann AA, Werren JH, eds. Influential Passengers. New York: Oxford University Press, 1-41.

13. Dobson SL, Bourtzis K, Braig HR, Jones BF, Zhou WG, Rousset F, O'Neill SL, 1999. Wolbachia infections are distributed throughout insect somatic and germ line tissues. Insect Biochem Mol Biol 29: 153-160.

14. Rousset F, Solignac M, 1995. Evolution of single and double Wolbachia symbioses during speciation in the Drosophila simulans complex. Proc Natl Acad Sci U S A 92: 6389-6393.

15. Hoffmann AA, Hercus M, Dagher H, 1998. Population dynamics of the Wolbachia infection causing cytoplasmic incompatibility in Drosophila melanogaster. Genetics 148: 221231.

16. Hoffmann AA, Turelli M, Harshman LG, 1990. Factors affecting the distribution of cytoplasmic incompatibility in Drosophila simulans. Genetics 126: 933-948.

17. Turelli M, Hoffmann AA, 1995. Cytoplasmic incompatibility in Drosophila simulans: dynamics and parameter estimates from natural populations. Genetics 140: 1319-1338.

18. Hoffmann AA, Turelli M, 1988. Unidirectional incompatibility in Drosophila simulans: inheritance, geographic variation and fitness effects. Genetics 119: 435-444.

19. Hawley WA, 1988. The biology of Aedes albopictus. J Am Mosq Control Assoc 4(Suppl): 2-39.

20. Service MW, 1995. Mosquito Ecology: Field Sampling Methods. London: Chapman and Hall.

21. Buei K, 1983. Pictorial Key to Species, Adult Mosquitoes in Thailand. Bangkok: PPHS Project, Series 3, Ministry of Public Health.

22. Rattanarithikul R, Panthusiri P, 1994. Illustrated Keys to the Medically Important Mosquitoes of Thailand. Bangkok: Wattana Panich Press.

23. Holden PR, Brookfield JFY, Jones P, 1993. Cloning and characterization of an fts $Z$ homolog from a bacterial symbiont of Drosophila melanogaster. Mol Gen Genet 240: 213-220.

24. Zhou W, Rousset F, O'Neill S, 1998. Phylogeny and PCR classification of Wolbachia strains using wsp gene sequences. Proc R Soc Lond B 265: 509-515.

25. Sinkins SP, Braig HR, O’Neill SL, 1995. Wolbachia pipientis: bacterial density and unidirectional cytoplasmic incompatibility between infected populations of Aedes albopictus. Exp Parasitol 81: 284-291.

26. Merçot H, Poinsot D, 1998. Wolbachia transmission in a naturally bi-infected Drosophila simulans strain from New Caledonia. Entomol Exp Appl 86: 97-103.

27. Clancy DJ, Hoffmann AA, 1998. Environmental effects on cytoplasmic incompatibility and bacterial load in Wolbachiainfected Drosophila simulans. Entomol Exp Appl 86: 13-24.

28. Perrot-Minnot MJ, Guo LR, Werren JH, 1996. Single and double infections with Wolbachia in the parasitic wasp Nasonia vitripennis - effects on compatibility. Genetics 143: 961-972.

29. Guillemaud T, Rousset F, 1997. Consequences of Wolbachia transmission process on the infection dynamics. J Evol Biol 10: $601-612$. 